\title{
"That's creepy, dude:" Disciplining desire and making masculine selves in the sexual moment
}

\begin{abstract}
How do men negotiate the boundary between romantic and creepy behavior in initial, sexualized interactions with women? In this paper, I argue that the discourse of "the creep," a stigmatized sexual figure, functions as a disciplinary mechanism that both creates and limits men's desire and sense of self in the tense initiation of a sexual moment. My analysis of 244 articles from 3 popular men's magazines suggests that an idealized sexual moment, as it is imagined in the pages of popular men's magazines, is fraught with the risk of miscommunication and the potential for failure. The figure of the creep on the cusp of a sexual moment signals a tension in the masculine self that, if resolved successfully, produce a particular heterosexual masculinity and access to women's bodies in an idealized sexual interaction. Furthermore, the discourse of the creep helps men manage these risks as they relate to feminist discourses about sexual harassment and violence. Ultimately, analyzing popular discourses of the creep reveals a set of cultural tensions threaded through heterosexual men's romantic interactions.
\end{abstract}

\section{Introduction}

In the current \#MeToo moment, men ${ }^{1}$ seem newly mystified about interactions with women and are continuing to ask questions about how to navigate dating and sex with women. As a recent Esquire article noted, "So as a new year begins, we hold this truth to be self-evident: When it comes to the pursuit of happiness, all men may not be equal creeps, but everyone is suspect" (Esquire 2018). Whole industries have emerged to help heterosexual, cisgender men navi-

\footnotetext{
${ }^{1}$ While men's magazines and research on gender are generally not explicit about men's gender identities, in this article, I assume that the men being discussed are cisgender men, or men whose gender identities align with the gender they were assigned at birth. How the discourse of the creep circulates, for example, in heterosexual relationships between trans men and trans or cis women, or in relationships between cis, trans, and nonbinary people are topics to be explored in future research.
} 
gate these moments, for example, popular “pick-up artist” seminars and resources (R. O’Neill 2018; Wallace 2017). Popular media have long provided guidance to men grappling with the complexities of contemporary dating practices, particularly given fluctuations in norms governing romantic behavior (Dowd and Pallotta 2000; Giddens 1993; Lamont 2015). Proper romantic behavior can seem downright mystifying to men seeking to engage in its scripts (Simon and Gagnon 1986), and romantic actions run the risk of being perceived as ridiculous, threatening, or obsessive (Lamb et al. 2018). For example, a quick internet search using the Boolean phrase "romantic or creepy" (web search 2018) yields more than seventeen million results, and the first five substantive articles are telling: "The Difference Between Romantic and Creepy," "When does being romantic become creepy?", "Fun debate: Romantic or creepy? Is she ungrateful and shallow?”, "The Difference Between Creepy And Romantic," and "What's The Difference Between Creepy and Romantic?"2 While not a representative sample of perspectives on romance and creepiness, these results suggest that romantic, dating scripts are far from solidified, and the stigmatized (Goffman 1963) figure of the "creep" lurks at the borders of romantic behaviors or "gestures."

I analyze the figure of the creep as a discursive product and impression management (Goffman 1959) device aimed particularly at men engaged in heterosexual dating practices, and I am focusing on the gendered and sexual aspects of creepiness, particularly as they apply to popular discourses about dating practices. ${ }^{3}$ I argue that the creep operates as a discursive device to

\footnotetext{
${ }^{2}$ The sources for these articles are, respectively, https://thoughtcatalog.com/mike-zacchio/2014/07/the-differencebetween-being-romantic-vs-being-creepy/, https://www.quora.com/When-does-being-romantic-become-creepy, https://www.whattoexpect.com/forums/hot-topics-1/topic/fun-debate-romantic-or-creepy-is-she-ungrateful-andshallow-1.html, https://www.theodysseyonline.com/the-difference-between-creepy-and-romantic, and http://www.escapistmagazine.com/forums/read/18.941186-Whats-The-Difference-Between-Creepy-and-Romantic, all accessed August 29, 2018.

${ }^{3}$ While terms like "creep" and "creepy" are also used to discipline women and LGBQ people, I focus here on heterosexual relationships and the ways men employ discourses of "the creep" to manage impressions and expectations around sexual behavior.
} 
help men negotiate the thorny, romantic, sexual moment in a way that ideally allows them to reaffirm a normatively masculine sexual reputation and achieve a short-term sexual goal. The sexual moment, as it is imagined in the pages of popular men's magazines (Waling 2017), is fraught with fears that align with feminist discourses about sexual harassment and violence (Hester, Kelly, and Radford 1996; Lloyd 1991; MacKinnon 1979; Armstrong, Gleckman-Krut, and Johnson 2018). Beyond the goal of sex, this moment also offers an opportunity for men to manage their sexual reputations (Plante and Fine 2017) and grapple with modern concepts of the masculine self and, predictably, the idealized self is marked by heteronormative constructs of masculinity that devalue perceived feminine behavior. Finally, I propose that, while the heterosexual, masculine self presented in discourses of the creep reinforces norms of hegemonic masculinity and stereotypes about men's sexual preferences, concerns about sexual violence embedded in the figure of the creep suggests that heterosexual men must discursively engage with risks of sexual violence against women.

In analyzing the role of the creep in men's popular media discourses about gender and sexuality, I propose that the creep demonstrates the impression management (Goffman 1959) men undergo to maintain a positive, masculine sexual reputation (Apostolidis and Williams 2017) in a possible sexual moment, illuminates the discursive negotiation of power at the level of idealized relationships, and challenges us to re-think the real possibilities of sexual egalitarianism in the context of heterosexual relationships. To address these three interconnected issues, I bring together theories of sexuality, gender, self, and crime, focusing particularly on sociologies of eroticism and the sexual moment, masculinities and normative masculine selves, and sexual harassment and violence. 
First, theorists of eroticism (Carrillo 2002; A. I. Green 2008b, 2008a; Shilling and Mellor 2010; Simon and Gagnon 1986; Weitman 1998) define the sexual moment as a time that is "set apart" from the everyday hustle of modern life, and they argue that the eroticism created and experienced around and within this moment is itself socially and psychologically constructed. We might locate theories of the sexual moment along a spectrum where, on the one hand, the sexual moment is seen as fully separate from everyday life and, on the other, where sexual moments are seen as partially or fully indistinguishable from social life. In The Night is Young (2002), Carrillo describes the sexual moment as a space apart from everyday reality, one with a clear threshold that must be crossed, and one where, once inside the sexual moment, everyday rules are suspended in favor of embodied spontaneity. Weitman similarly describes "erotic reality" as a realm that is separate from everyday life and is, as Weitman argues, a social construction imbued with a host of characteristics including rules about the body, pleasure, giving and receiving, aesthetics, exclusivity, mutuality, and trust (Weitman 1998). Giddens takes a slightly different, more rationalized approach when he suggests that intimacy "should not be understood as an interactional description, but as a cluster of prerogatives and responsibilities that define agendas of practical activity" $(1993,190)$. In all three cases, the sexual moment is clearly bounded by particular rules and responsibilities, scripts (Simon and Gagnon 1986) which, if transgressed, function to "kill the moment" (Carrillo 2002, 198).

However, everyday life pervades the sexual moment, as researchers of hookup culture have argued (Wade 2017; Bogle 2008; Hamilton and Armstrong 2009). Whittier and Simon describe desire as a multidimensional "fuzzy matrix" that is embedded in everyday social life, and they note that "It is easy to see how social the sexual is when one notes that the patterns of idiosyncratic desires flow from all that which is social - racism, sexism, ageism, romanticism, etc. 
All social values and beliefs are complexly present and visible." (2001, 162). For Whittier and Simon, overarching social structures are implicated in contexts of eroticism. Green offers the concept of "erotic habitus" to suggest, among other things, the ways in which erotic life as manifested in behavior, the unconscious, and bodies are actively structured by individuals' social locations (A. I. Green 2008a). Finally, Weitman introduces the idea of "socioerotic life," suggesting that erotic life and social life are subject to similar kinds of rules, trajectories, rites, and practices (Weitman 1998, 96). Simultaneously, Weitman acknowledges the ways in which "socioerotic realms" like the sexual moment are intended to provide participants a respite from everyday "social violences" $(1998,100)$. In brief, the sexual moment remains an unequal space, even as its participants hope for a moment apart from everyday life (Lamb et al. 2018; Montemurro and Riehman-Murphy 2018; Almog and Kaplan 2017) ] In the pages of men's magazines, the sexual moment enabled and constrained by the figure of the creep demonstrates both sides of the sexual moment: a special space distinct from the mundane and a space structured by ongoing gendered, racialized, and classed inequalities.

The sexual moments imagined in men's magazines presume a particular masculine self, and sociologies of masculinities and self offer ways to frame the production of masculine selves in the modern world. Hegemonic masculinity (R. W. Connell and Messerschmidt 2005; R. Connell 2005; Messerschmidt 2018) pervades men's popular media (K. Green and Oort 2013; Tan et al. 2013; Messner and Montez de Oca 2005), and clear-cut sexual scripts privilege the development of unemotional masculine selves (Montemurro and Riehman-Murphy 2018). However, the modern, masculine self seems ambivalent on the subject of sexual intimacy and emotions (Lamont 2015; Eisen and Yamashita 2017). On the one hand, it would seem, according to some sociologists, that men may be looking for more emotional authenticity in their sexual experiences. 
Elizabeth Bernstein proposes the concept of "bounded authenticity" to suggest that a particular group of men — "clients" of sex work, in this case—-seek not just a "quick release" sexual experience but a more authentic, genuine, pleasurable experience that is clearly limited by the financial constraints of the transaction (2007). However, beyond a search for emotional authenticity, some have suggested that men's actual feelings about sexual intimacy are much more complex, and men express a feeling of anxiety around desires for sexual and emotional intimacy (Seal and Ehrhardt 2003), anxiety that still manifests in the perpetuation of gender inequality (Lamont 2015). I demonstrate below the ways that this anxiety manifests in the figure of the creep, with mixed results.

If sexual scripts governing the sexual moment also function to integrate sexual selves with sexual practice (Simon and Gagnon 1986), substantial confusion around masculinities, emotions, and appropriate behavior are understandable. Discourses of the creep both inculcate and respond to this sense of anxiety about the role of emotional intensity in men's negotiations of self. While, in this paper, I am not exploring the effects of the discourse of the creep on men's actual self-perception and behavior, I am suggesting that the figure of the creep offers men a concrete idea around which to organize their anxieties about their constructions of the masculine, heterosexual self.

A final theoretical foundation for the figure of the creep may be found in sociological analyses of sexual harassment and violence. Sociologists (Dunn 1999; Smith and Morra 1994; Uggen and Blackstone 2004; Seal and Ehrhardt 2003; Emerson, Ferris, and Gardner 1998; Williams, Giuffre, and Dellinger 1999; Armstrong, Gleckman-Krut, and Johnson 2018) address the complicated relationships of power that produce women's experiences of sexual violence as an everyday phenomenon. Jennifer Dunn, for example, explores the ways women understand and 
negotiate "forcible interaction" as a range of behaviors (from unwanted attention to stalking),

particularly in intimate relationships among undergraduate sorority women and men (1999).

Women do experience everyday kinds of sexual intimidation and harassment that often produce fears of sexual violence, as in the case of women's experiences of harassment by telephone and in the workplace (Smith and Morra 1994; Uggen and Blackstone 2004). Furthermore, researchers are increasingly exploring the always-emerging online dimensions of sexual violence, where women face yet another arena of harassment and violence (Thelwall 2011; Powell and Henry 2017; Nicholas and Agius 2018).

What is most relevant about the persistence of sexual violence in women's lives for the case of the creep is the very "everydayness" of fears of sexual violence. Moments of courtship offer sites of tension where the interpretations of romantic interactions as loving or violent seem to teeter on the brink. Emerson et al argue that:

Many forms of what comes to be identified as stalking grow out of glitches and discontinuities in two very common and normal relationship processes-coming together and forming new relationships on the one hand, and dissolving and getting out of existing relationships on the other. In this way the processes and experience of being stalked are intricately linked to normal, everyday practices for establishing, advancing, and ending relationships. $(1998,290)$

Similarly, Dunn argues that violence and love are not as distinct as some researchers claim, and she highlights romantic interactions as a source of possible threat for women especially (1999). More recent cases of sexual violence perpetrated by celebrities and powerful political and academic figures again highlight the very "everydayness" of sexual violence and the ways violence and romance are tightly connected in American popular culture.

The discourse of the creep suggests that men's magazines are aware of the reality of sexual violence as a source of fear in women's lives. In fact, so much of the figure of the creep is organized around responding to fears of sexual violence that it might not be too extreme to sug- 
gest that there is a "discursive explosion" (Foucault 1976) around sexual violence in men's magazines. Interestingly, Anthony Giddens suggests that "womanisers" (a possible precursor to the figure of the creep) "are seducers in an era in which seduction has virtually become obsolete," and he adds that "'Seduction' has lost much of its meaning in a society in which women have become much more sexually 'available' to men than ever before, although—and this is crucial— only as more equal" (Giddens 1993, 83). My evidence, presented below, suggests that seduction is far from obsolete (Almog and Kaplan 2017; R. O'Neill 2018; Wallace 2017) and that the complex process of seduction, particularly as it is organized by the figure of the creep around fears of sexual violence, are still quite relevant to the way (men's magazines argue) men should be organizing their pursuit of women in public arenas. For Dunn, seduction scripts are productive in that they allow men to walk the fine line between achieving a romantic connection and being seen as a "stalker" or sexual predator (1999). In what follows I present evidence for the opposite case, specifically, that the discourse of the creep as a "new script" (Seal and Ehrhardt 2003, 297) that operates negatively among men, as a stigmatized script that, men's magazines suggest, men should keep in mind and avoid as they walk the fine line between romance and rejection.

\section{"The Creep" in Popular Men's Magazines}

Here, I am focusing on discourses of "the creep" as articulated by both men and women who have contributed articles, questions, and responses in popular men's magazines. While my data are drawn from popular men's general interest magazines, it is important to keep in mind that the magazines themselves are cultural products (Tan et al. 2013; Messner and Montez de Oca 2005). As such, they may reflect cultural ideals, but whether they reflect men's experiences and cognition remains an open question and an avenue for further research. In this paper I analyze culturally-specific, idealized sexuality as a model presented through popular media, particu- 
larly given cultural ideals as sources for behavior in romantic and erotic interactions (Giddens

1993; Swidler 2003; Weitman 1998). In brief, I maintain that popular men's magazines are both products of and active creators of idealized men's (hetero)sexuality in the contemporary U.S. Furthermore, I suspect that romantic, cultural ideals differ (slightly or significantly) from the ways in which women understand and use "the creep" in popular media and they also likely differ from men's and women's lived experiences of negotiating romantic relationships. While my goal is to excavate the ways in which "the creep" both reflects and creates heterosexual masculine sexuality, I address these opportunities for further study in the conclusion below.

To these ends, I sought the most popular men's lifestyle magazines defined in terms of circulation (Appendix A). Given my interest in relationships, particularly sexual relationships, I excluded more general interest magazines like Popular Science and Popular Mechanics and sports-centered magazines like Field and Stream and Sports Illustrated. For the limited purposes of this preliminary analysis, I also excluded three popular magazines that were not available online: Playboy, Maxim, and Men's Journal. ${ }^{4}$ My data include articles from three of the top fifteen most popular magazines, in terms of circulation, from the first year of articles available in online databases: Men's Health (1991-2018), GQ (1997-2018), and Esquire (1996-2018). While it is difficult to capture the demographic profile of consumers of these magazines, the press kits for these magazines provide some insight into the target market for the magazines. While income data suggest that, in all cases, consumers are largely middle-class men, the profiles of these magazines' primary consumers did not include race or sexual orientation. In all cases, I conducted a search of articles available in the aforementioned date ranges using the search term "creep*" to

\footnotetext{
${ }^{4}$ It is unclear whether archival research involving these two magazines would deepen or challenge the preliminary findings briefly outlined in this paper, given the consistency of "the creep" across the four magazines analyzed herein. Future research could involve a limited, random sample of these magazines to test whether and how the figure of the creep relates to the key themes of this paper.
} 
capture all permutations of the word "creepy" (which returned terms like creep, creepy, creeper, and creepiness). My searches returned 286 articles in Men's Health, 165 in GQ, and 410 in Esquire.

A preliminary review of the sample resulted in a subsample of articles that referred to human behavior in actual, potential, or imagined romantic or sexual relationships primarily between men and women, but also between men and men, men and animals, and men and objects. This broad-based approach resulted in a wide variety of articles including celebrity interviews, advice columns, journalistic exposés, fiction, and product reviews. I excluded articles that referred to non-human items creeping in a non-sexual way ${ }^{5}$ or references to scenarios or films in which the meaning of creepy was a clearly non-sexual "scary." This search method produced 92 articles from Men's Health, 47 articles from GQ, and 105 articles from Esquire.

\section{Imagining the Sexual Moment, Bounded by Creepiness}

In terms of the sexual moment, advice columns in men's magazines in particular use the figure of the creep to provide guidelines for how to successfully initiate and execute a sexual moment. Interestingly, the creep highlights the ways in which "the look" is a critical threshold for heterosexual men (Carrillo 2002). A Men's Health article about picking up women with a look offers the following advice:

Here's a pickup tip: After catching her eye, go in for her mind. British researchers found that women aren't attracted to men who initiate eye contact and then quickly break it. An averted gaze sends the signal that you're more interested in something (or somebody) else, say the study authors. Of course, there's a fine line between a come-hither look and a creepy stare. Keep it friendly by focusing on women who are close by--you'll be able to lock eyes and then immediately step up to start a conversation. ("If Looks Could Thrill" 2008)

A similar Men's Health article about seducing a female stranger at a bar advises men to:

\footnotetext{
${ }^{5}$ Interestingly, among the list of nonsexual things that creep, a few themes emerged, particularly related to physical health and appearance. The most frequently mentioned things that creep? Hair lines, stomach acid, and sleeves.
} 
Look around the room. Nothing turns a woman on as quickly as a guy who looks her straight in the eye while talking to her. Then again, nothing turns her off as quickly as a guy who looks her straight in the eye while talking to her. The trick is to show her you're interested without coming off as creepy. "Glance deeply into her eyes to punctuate two consecutive sentences, then on your third, move your gaze off to nowhere," says Pamela Regan, Ph.D., a professor of psychology at California State University at Los Angeles. She'll be drawn to you--and the Mace will stay safely in her purse. (Martelli 2001)

In a third example, online contexts offer a particular set of risks for men seeking to initiate a romantic relationship. In an article titled "No More Shirtless Selfies: GQ's Guide To Dating Online; Without Being a Perv, a Wuss, Or The Guy Who Ends His Messages With a ;)," the anonymous author notes that:

Ten years ago, online dating was like looking at porn or listening to John Mayer: You did it, but you would never, ever admit to it. Now clicking through pages of potential girlfriends (or freaky hookups) is an acceptable - hell, expected - part of being a single guy. It's also a confusing, intimidating, booby-trapped part of singledom. Do you tell her she's sexy in the first message? (Nope, that's creepy.) (Anon 2013)

In the later step-by-step guide, step 10 includes the following advice: "It's counterintuitive, but mentioning a woman's looks in your first e-mail comes off as creepy-like you've started fapping [masturbating]. Compliment her ironic Kanye shades, sure — just not any part of her actual body" (Anon 2013). A more recent Esquire article titled "Hacking Chivalry" outlines dating app practices that allow men to avoid the stigma of the creep (Black 2017). Although the advice these articles present seems internally contradictory, the figure of the creep suggests that looking can go "too far," eliminating the possibility of a sexual moment being initiated. In other words, the creep mediates a particular tension as men approach the threshold of the sexual moment: specifically, look, but not too hard.

A similar tension is captured in a pair of quotes about the formal chivalry with which men should treat women on a date. In the first Men's Health article, actress Anita Briem explains how to "snag her attention": 
A man should never act "too cool for school," she says. Do that and you're doomed from the start. "When someone comes up to you and starts to make conversation but pretending it's not a big deal, like he didn't really come over just to talk to you, that's creepy. It's okay to go up and say. "Hi, I don't know you, but I'd like to introduce myself." That's clarity, and clarity is good. (Vontz 2008)

In contrast, a Men's Health article describing "old-school courtship" suggests that men should:

Pull out her chair. This should not be done formally, as a butler would. We know a guy who creeped women out by calling them "milady" as though he were on PBS. It should be casual but deliberate, with one hand, as a sign of respect, not servitude. If it involves any scurrying to get where you'd have to be, skip it. (H. O’Neill 2002)

In these two cases, the figure of the creep emerges as someone who is either too disinterested or too interested, in either case, spoiling the possibility of a sexual moment. A final quote from a recent $G Q$ article captures this tension nicely: "There's a fine line between chivalry and posturing. Holding the door? Yes. Getting up each time your date does? A bit creepy” (O’Brien 2010). Determining the appropriate level of chivalrous behavior allows men to avoid the stigmatized stain of the creep while maintaining access to a possible sexual moment.

Assuming that men have navigated the complicated courtship practices without seeming creepy, articles also advise men on how to negotiate the sexual moment itself. In a Men's Health article that features a play-by-play set of timed instructions to get a date to sex: "11:15 Unwind Afterward. Do not suggest that she'd better make a move or she'll miss the last bus. Do not confess undying love, as this is generally seen as creepy after the first session. Hold her in your arms and whisper drowsily, as she dozes off, "You are so sexy"” (“Tonight's the Night." 1997). Here, the instructions for men are a bit clearer: the creep is someone who is too emotionally engaged, too intense, but some intensity is required for sexual success.

In terms of the everydayness of the erotic, men's magazines use the creep to emphasize the access men have (or should have) to erotic imaginings of women's bodies. Heterosexual men's “erotic habitus" (A. I. Green 2008a) is structured by visual access to women's bodies. 
Men's magazines are rife with advice on how to look at women and how to make a more generalized sense of eroticism into a tangible sexual encounter-or at least start to. But this access does have a limit, as the following article from Men's Health suggests. In this article, readers were asked to indicate whether men could "leer" at women dressed in skimpy clothing. One man responded:

If a woman dresses provocatively, [is] it a man's right to stare? Yes. But be a gentleman about it. Look, don't leer--you are definitely at risk of creeping the girl out. But looking at women is nothing to be ashamed of. Those women who bust you or make you feel like crap for looking at them should go home and put on a robe. Maybe a nice short robe, sheer, with li'l flowers on it and the backside cut out. MIKE, 35. ("A Case of Leer." 2004)

The fine line between "the look" and "the stare" is also articulated in the following Men's Health article authored by a woman with "large breasts":

My advice, should you find yourself chatting with an amply endowed female, is to practice restraint. It's not that we mind you looking at our breasts; it's just that seeing you do it is creepy. The stare, obviously, is bad, and the quick, subtle glance is never as quick or subtle as you hope. Try using your powers of reconnaissance; stare sideways at a woman while you're talking to another man, and then, later, when you start up a conversation with her, look her in the eye while enjoying the mental picture of her breasts. (Miller 2002)

The implication in both of these quotes is that women's bodies are available for eroticization for men (even women agree!), within limits; the implication is that the sexual moment is circumscribed by mysterious rules men must learn to navigate. Furthermore, imagining women's bodies is framed as central to heterosexual men's erotic habitus, but communicating this imagination process to women causes the imagined sexual moment or the possibility of a sexual moment to evaporate. The creep operates as a signpost to help men determine when and how to transition from an imagined to a real sexual moment, and he is characterized as inherently interested in sex, but not overly expressive of this interest.

\section{The Creep and the Masculine Self}


In addition to helping men mediate the imagined sexual moment, the creep also marks a unique tension in the modern, masculine self. Sociological theorists of masculinity and sexuality suggest that projects of the modern, masculine self involve negotiating the role of emotion and emotional intensity in men's lives (Bernstein 2007; R. Connell 2005; Giddens 1993; Eisen and Yamashita 2017; Hartman 2017). The mix of sexual and emotional intimacy seemingly required in the modern world offers mixed messages to heterosexual men, and the figure of the creep emerges to highlight and, ideally, resolve the tension between emotional, romantic relationships and emotionally disengaged heterosexual, hegemonic masculinity. This tension is perhaps most evident in one Men's Health article titled "Men We [women] Can't Say No To," written by Nicole Beland. Beland states that:

As a college student, I fell head over platform shoes for a chef who devoted an entire weekend to wooing me by cooking elaborate meals in an apartment we never left. I was impressed by his pesto, but knocked out by his gusto - he wanted me, he was determined, and it was intoxicating. I've heard from guys who swear that such behavior often backfires-women think it's too much, too creepy. In some cases, I suppose that's true. All I know is that the chef went after what he wanted, and he got it. (2004)

What are men to do with this kind of story? How should they construct a sense of self in response to the possibility that emotional intensity in men may both be desired and rejected by women "experts?" The role of women as expert advisors on creepiness is significant here, although the message is confusing, and men's emotional openness is persistently at risk of being evaluated by women. Men must manage both their emotions and women's perceptions of their emotions. A second example offers a further illustration of women's evaluation of men's selfpresentation (Goffman 1959). In an article titled "No, You're Not Perfect," author Julie Stewart corrects men's overly confident selves, stating that:

Just because she's looking doesn't mean she wants you. Research published in the journal Psychological Science shows that men frequently overestimate women's sexual interest... The problem is, you can seem creepy if you come on too strong. Your fix: Every time 
you go to a restaurant or a movie theater, observe how couples interact. Soon you'll be a whiz at detecting subtle mating cues, Dr. Dobransky says. (Stewart 2012)

Stewart links emotional or sexual intensity, or "coming on too strong," to men's inflated sense of self, and the figure of the creep disciplines an overly confident masculinity. However, the creep also delimits an "insecure" masculinity; in another Men's Health article titled "6 Secret Ways to Turn Her On," the author advises men to "ditch the cell," arguing that:

When chatting on the phone, you can't help but reveal some of the ins and outs of your work or private life, and that kind of openness is girly, creepy, and not sexy. But here's the biggest problem: Any guy who can't go 2 hours without checking in with his friends, his job, his family, comes across as desperately insecure. Go ahead and actually turn it off in front of her. She will recognize you as the man who is comfortable and at peace with what's in front of him, and thank her stars you're not the guy who's always wondering what and who is next. (Miller 2004)

I suggest that this quote articulates a more implicit sense of emotional intensity, and the figure of the creep here is a man who is too emotionally engaged with "his friends, his job, his family," and, notably, at risk of being feminized. A final set of examples demonstrate that men should negotiate emotional intensity only in relationship to a female partner; in other words, emotional intensity with other men lands them squarely into "no homo" territory (Pascoe and Diefendorf 2018). Men's emotional intensity with other men are universally marked as "creepy," as the case of Donald Trump's presumed relationship with Vladimir Putin demonstrates in the pages of $G Q$ (Flynn 2017) and obliquely referenced in Esquire (Junod 2014).

The broader implication here is that men should construct a limited, emotional sense of self in the context of a relationship with a woman. While the figure of the creep marks the boundaries of the idealized, masculine self, these boundaries remain unclear. I suggest that the creep operates more as a marker of cultural tension than an ideal that clearly resolves these tensions. In other words, I propose here that an analysis of the creep offers evidence of the kinds of modern tensions that cross-cut heterosexual men's romantic experiences. However, the figure of 
the creep in these examples remains unresolved, and, in some ways, the confusing, contradictory advice continues to emerge in popular men's magazines.

\section{The Risk of Creepiness: Managing Implied Sexual Violence}

Within the discourse of the creep articulated in the preceding excerpts, a particular boundary emerges that men must manage. This anxiety-laden boundary separates the realm of acceptable courting behavior from behavior that might be read as threatening toward women, which men, ideally, want to avoid. Based on the ways men's magazines articulate "the creep," a range of seemingly innocuous behaviors might be read as menacing, particularly as indicators of possible sexual violence. On the one hand, women do face the real threat of sexual violence, and anxieties about women's anxieties about sexual violence pervade the discourse of the creep. On the other hand, men's magazines use the discourse of the creep to offer a set of admittedly complex "sexual scripts" (1986) to help men manage these anxieties about anxieties. In what follows, I present three cases that highlight the tension between the threat of sexual harassment and violence that the creep exemplifies and the alternative, "better" solution.

In one Esquire article, A.J. Jacobs sets up an online dating account for his "hot" nanny in an effort to find her a date. He screens her responses and notes that "One suitor tried to seduce me with this line: 'I would like to stalk you.' Another said, 'I am in a committed relationship but am looking for a girl on the side.' Honest? Sure. To the point? Yes. Creepy? As hell.” (2007). Although unsuccessful in his attempt to secure a relationship for his nanny, Jacobs later predicts that she will "find [chemistry] with someone...because of the men themselves. The only thing more surprising than the quantity and deviousness of the creeps was the emotional honesty and fragility of the noncreeps" (2007). The case of the creep functions here as examples of "what not to do" specifically in the context of online dating. The sexual script of the creep as Jacobs pre- 
sents it is one of failure, and that failure is marked by the articulation of sexual violence ("stalk you"). Still, the line between harassment and love remains unclear. On the one hand, Jacobs clearly values "emotional honesty and fragility" in "noncreeps." On the other hand, apparently, many men are devious "creeps," which is simultaneously an acknowledgement that sexual violence from men is a real possibility for women and that excessive honesty might reveal the creepy truth about any one man.

A second example further illustrates the connection between the sexual script of the creep and implied sexual violence against women. In a Men's Health article that includes excerpts from a book of "bad boyfriend stories," the anonymous author describes a story from the book:

Jesse rubs Carrie's back; she watches TV. Annoyed, he says, "What does somebody have to do to get your attention? Wrap a bullwhip around your neck?" Better move: The creepy threat was mistake number two; number one was assuming touch would keep her attention. "Women can compartmentalize physical come-ons, especially if they're not in the mood," says Pat Love, coauthor of How to Improve Your Marriage Without Talking About It. Instead, ask open-ended questions. "It shifts her attention to you. Once you have it, she'll be more open to seduction," Love says. ("Handle with Care." 2009)

Clearly, the implied sexual violence in "Jesse's" careless comment is "creepy." What is unique about this scenario, though, is that Jesse himself is not labeled a creep; it is his comment that is creepy, and he should have chosen a "better move" to communicate his desire. This quote suggests that creepiness is a sexual script that "everyman" like Jesse has internalized, and it runs the risk of being expressed accidentally, thus ending the possibility of a sexual encounter. In both of these cases, the creep operates as a "mood killer" (Carrillo 2002), ending access to the sexual moment and shutting down any possible shared eroticism. Furthermore, the connection between the sexual script of the creep and sexual violence against women is clear, although precisely how men should manage the risk of a perception of sexual violence (particularly if it is present in "most" men) remains unclear. 
The presence of workplace sexual harassment looms large in a final example. Writing

about how to manage office romances, Men's Health authors Porter and Ogden explain that:

For Grant and Amanda, the romance seemed to go wrong even before it had the chance to go right. She wanted to remain friends. He wanted all or nothing. Under normal circumstances, a guy might be persistent. But in the office, persistence can translate into creepiness, which can translate into a call from HR. In short: Grin and bear it. As awkward as it was, that's just what Grant did. "I was so furious," he says. "There was a period of silent treatment." (2012)

The tension here between the workplace and "normal circumstances" is telling: men's persistence in the office is creepy and may warrant "a call from HR," while persistence outside the workplace is implicitly tolerable. In the workplace, the risk of sexual harassment is marked by the figure of the creep and managed by the organizational power of Human Resources, which has presumably adopted sexual harassment policies following feminist organizing efforts (MacKinnon 1979). In this final example, workplace creepiness may be interpreted sexual harassment and, at least in this case, the solution for men is clear; in the realm of workplace romances, "grin and bear it." In each of these three examples, the figure of the creep marks a potential for men's behavior to be interpreted as sexual harassment or violence against women. In the workplace, where explicitly disciplinary policies exist, a solution for men is clear, while in the nonworkplace dating realm, solutions are less obvious.

\section{Conclusion: Managing the Stigmatized Creep}

In sum, I have argued that the discourse of "the creep" as articulated in popular men's magazines offers an imagined, stigmatized locus around which men grapple with ideas about sexual violence against women and the modern, heterosexual, masculine self as they negotiate access to a distinctly erotic "sexual moment" with women. The creep marks a key set of tensions in American masculinity: between emotional intimacy and distance, around limited but persistent access to women's bodies, and between sexual violence and safety. In terms of progress toward 
eradicating sexual violence, analysis of the creep suggests that the news is mixed. The evidence from men's magazines indicates that the discourse of the creep is used to help men respond to women's legitimate claims about sexual violence, on the one hand. "The creep" is a negative figure who might be perceived as a stalker or sexual predator and, as such, he falls firmly outside the realm of legitimate sexual behavior and limits possibilities for women's sexual citizenship (Weeks 1998). On the other hand, the discourse of the creep allows men to maintain the desire for and illusion of control over women's bodies, particularly in public realms like bars. "The creep" here helps men negotiate the boundary between appropriate and inappropriate visual, verbal, and physical contact, often with the idea that men are entitled to at least look at, if not approach, women. In most cases, men are seeking admission into an imagined sexual moment, and the figure of the creep may help them determine how best to access that moment without being denied.

While I have focused on a particular cultural context in this paper (American men's lifestyle magazines), future research on the figure of the creep would engage critically with a number of intersecting themes. Men's interpretations of such discourses, for example, could be explored further. Whether and how men perceive a risk of being interpreted as creepy in dating interactions and, significantly, adjust their behavior accordingly would yield fruitful insights into how heterosexual men negotiate modern, masculine selves. Women, too, are central to this interactional negotiation process, as their presences as disciplinary "experts" in the above articles suggests, and a full exploration of these processes of "doing" masculinity (Messerschmidt 2009; West and Zimmerman 1987). Interviews with both men and women would further flesh out the function of the creep. 
Research exploring the intersection of race, gender, and sexuality in the figure of the creep would add to current literature exploring race, gender, and dating (Robnett and Feliciano 2011; Kalmijn 1998; Buggs 2017; Holland 2012; McClintock 2010). While very few articles referred explicitly to race, unpacking how the figure of the creep is racialized could reveal how racism and racial inequalities persist in romantic and sexual practices. For example, future research might consider whether the figure of the "creep" operates differently among different racial groups, perhaps with adjacent terminology, or whether the "creep" is racialized in a particular way (as a primarily white man, for example). Future research might also examine whether behaviors seen as "creepy" among white men are criminalized among men of color, suggesting vastly different stakes for men of color. Relatedly, how the creep functions in online contexts (Pascoe 2011; Nicholas and Agius 2018; Ging 2017; Lin and Lundquist 2013), particularly with the explosion of online dating and hook-up websites and apps, briefly referenced above, represents a distinct area of future research for cisgender, heterosexual men and women as well as LGBTQ people.

Furthermore, a similar project using popular women's magazines might yield a similar result but perhaps with different implications for women's constructions of sexual goals, moments, eroticism, selves, and violence. I have not addressed how men understand women as creepy, although the few of these cases that appeared in my data suggest that women are "creepy" primarily when they challenge men's authority. A parallel term about women might be "crazy," although I suspect it functions differently from the term "creepy." Finally, I have also not discussed how the creep is constructed and used (if at all) in relationship negotiations among LGBTQ people, although the presence or absence of this figure might yield some interesting new insights into the gendered nature of romantic relationship negotiations. Engaging in a larger pro- 
ject using data from a range of popular women's and LGBT cultural texts like magazines, websites, social media apps, and blogging platforms like tumblr would deepen these initial observations and help us understand how individuals grapple with the complex, interconnected matrix of relationships and selves in distinctly modern, anxiety-ridden contexts. 


\section{References}

“A Case of Leer." 2004. Men's Health 19 (6): 40.

Alliance for Audited Media. 2013. "Consumer Magazines - Search Results for Men's Magazines.” June 30, 2013. http://abcas3.auditedmedia.com/ecirc/magsrdssearch.asp.

Almog, Ran, and Danny Kaplan. 2017. "The Nerd and His Discontent: The Seduction Community and the Logic of the Game as a Geeky Solution to the Challenges of Young Masculinity." Men and Masculinities 20 (1): 27-48. https://doi.org/10.1177/1097184X15613831.

Apostolidis, Paul, and Juliet A Williams. 2017. "Sex Scandals, Reputational Management, and Masculinity under Neoliberal Conditions.” Sexualities 20 (7): 793-814. https://doi.org/10.1177/1363460716658405.

Armstrong, Elizabeth A., Miriam Gleckman-Krut, and Lanora Johnson. 2018. "Silence, Power, and Inequality: An Intersectional Approach to Sexual Violence." Annual Review of Sociology 44 (1): null. https://doi.org/10.1146/annurev-soc-073117-041410.

Beland, Nicole, Susan Dominus, Sarah Hepola, and Majka Burhardt. 2004. "“Men We Can’t Say No To'." Men's Health 19 (7): 174-75.

Bernstein, Elizabeth. 2007. Temporarily Yours: Intimacy, Authenticity, and the Commerce of Sex. 1st ed. Chicago, IL: University Of Chicago Press.

Black, Julia. 2017. "Hacking Chivalry." Esquire, August 2017.

Bogle, Kathleen A. 2008. Hooking Up: Sex, Dating, and Relationships on Campus. 1 edition. New York: NYU Press.

Buggs, Shantel Gabrieal. 2017. "Does (Mixed-)Race Matter? The Role of Race in Interracial Sex, Dating, and Marriage." Sociology Compass 11 (11): e12531. https://doi.org/10.1111/soc4.12531.

Carrillo, Hector. 2002. The Night Is Young: Sexuality in Mexico in the Time of AIDS. Chicago, IL: University Of Chicago Press.

Connell, R. W., and James W. Messerschmidt. 2005. "Hegemonic Masculinity: Rethinking the Concept." Gender and Society 19 (6): 829-59.

Connell, Raewyn. 2005. Masculinities. Berkeley, Calif.: University of California Press.

Dowd, James J., and Nicole R. Pallotta. 2000. "The End of Romance: The Demystification of Love in the Postmodern Age." Sociological Perspectives 43 (4): 549-80.

Dunn, Jennifer L. 1999. "What Love Has to Do with It: The Cultural Construction of Emotion and Sorority Women's Responses to Forcible Interaction." Social Problems 46 (3): 44059.

Eisen, Daniel B., and Liann Yamashita. 2017. "Borrowing from Femininity: The Caring Man, Hybrid Masculinities, and Maintaining Male Dominance." Men and Masculinities, September, 1097184X17728552. https://doi.org/10.1177/1097184X17728552.

Emerson, Robert M., Kerry O. Ferris, and Carol Brooks Gardner. 1998. “On Being Stalked.” Social Problems 45 (3): 289-314.

Esquire. 2018. "Dubious Achievement Awards 2017," Winter 2018.

Flynn, Sean. 2017. "Putin Enemy No.1." GQ: Gentlemens Quarterly, December 2017.

Foucault, Michel. 1976. The History of Sexuality, Vol. 1: An Introduction. New York, NY: Vintage.

Giddens, Anthony. 1993. The Transformation of Intimacy: Sexuality, Love, and Eroticism in Modern Societies. Stanford, CA: Stanford University Press. 
Ging, Debbie. 2017. "Alphas, Betas, and Incels: Theorizing the Masculinities of the Manosphere." Men and Masculinities, May, 1097184X17706401. https://doi.org/10.1177/1097184X17706401.

Goffman, Erving. 1959. The Presentation of Self in Everyday Life. New York, NY: Anchor.

-1963. Stigma: Notes on the Management of Spoiled Identity. New York, NY: Simon \& Schuster.

Green, Adam Isaiah. 2008a. "Erotic Habitus: Toward a Sociology of Desire." Theory and Society 37: 597-626.

- 2008b. "The Social Organization of Desire: The Sexual Fields Approach." Sociological Theory 26 (1): 25-50.

Green, Kyle, and Madison Van Oort. 2013. "WWe Wear No Pants': Selling the Crisis of Masculinity in the 2010 Super Bowl Commercials." Signs 38 (3): 695-719.

Hamilton, Laura, and Elizabeth A. Armstrong. 2009. "Gendered Sexuality in Young Adulthood: Double Binds and Flawed Options.” Gender \& Society 23 (5): 589-616. https://doi.org/10.1177/0891243209345829.

“Handle with Care." 2009. Men's Health 24 (2): 52.

Hartman, Tova. 2017. "Men, Masculinity, and Breakups: Resisting the Tyranny of 'Moving On."” Personal Relationships 24 (4): 953-69. https://doi.org/10.1111/pere.12223.

Hester, Marianne, Liz Kelly, and Jill Radford. 1996. Women, Violence, and Male Power: Feminist Activism, Research, and Practice. Buckingham; Philadelphia: Open University Press.

Holland, Sharon Patricia. 2012. The Erotic Life of Racism. Duke University Press Books.

"If Looks Could Thrill." 2008. Men's Health 23 (2): 48.

Jacobs, A. J. 2007. “My Life as a Hot Woman.” Esquire 147 (5): 116-38.

Junod, Tom. 2014. "Alternative Emmy for Creepy Sex.” Esquire, August 2014.

Kalmijn, Matthijs. 1998. "Intermarriage and Homogamy: Causes, Patterns, Trends." Annual Review of Sociology 24 (1): 395-421.

Lamb, Sharon, Elena V. Kosterina, Tangela Roberts, Madeline Brodt, Meredith Maroney, and Lucas Dangler. 2018. "Voices of the Mind: Hegemonic Masculinity and Others in Mind during Young Men's Sexual Encounters.” Men and Masculinities 21 (2): 254-75. https://doi.org/10.1177/1097184X17695038.

Lamont, Ellen. 2015. "The Limited Construction of an Egalitarian Masculinity: CollegeEducated Men's Dating and Relationship Narratives." Men and Masculinities 18 (3): 271-92. https://doi.org/10.1177/1097184X14557495.

Lin, Ken-Hou, and Jennifer Lundquist. 2013. "Mate Selection in Cyberspace: The Intersection of Race, Gender, and Education." American Journal of Sociology 119 (1): 183-215.

Lloyd, Sally A. 1991. "The Darkside of Courtship: Violence and Sexual Exploitation." Family Relations 40 (1): 14-20.

MacKinnon, Catharine A. 1979. Sexual Harassment of Working Women: A Case of Sex Discrimination. New Haven: Yale University Press.

Martelli, Rose. 2001. "Seduce Her in Seconds." Men's Health 16 (4): 108.

McClintock, Elizabeth Aura. 2010. "When Does Race Matter? Race, Sex, and Dating at an Elite University." Journal of Marriage and Family 72 (1): 45-72. https://doi.org/10.1111/j.1741-3737.2009.00683.x.

Messerschmidt, James W. 2009. “'Doing Gender': The Impact and Future of a Salient Sociological Concept." Gender and Society 23 (1): 85-88. 
2018. Hegemonic Masculinity: Formulation, Reformulation, and Amplification. Rowman \& Littlefield.

Messner, Michael A., and Jeffrey Montez de Oca. 2005. "The Male Consumer as Loser: Beer and Liquor Ads in Mega Sports Media Events." Signs: Journal of Women in Culture and Society 30 (3): 1879-1909. https://doi.org/10.1086/427523.

Miller, Sarah. 2002. "Breasts: A Love Story." Men's Health 17 (1): 95.

—. 2004. "6 Secret Ways to Turn Her On." Men's Health 19 (9): 138-40. https://doi.org/Article.

Montemurro, Beth, and Christina Riehman-Murphy. 2018. "Ready and Waiting: Heterosexual Men's Decision-Making Narratives in Initiation of Sexual Intimacy." Men and Masculinities, January, 1097184X17753040. https://doi.org/10.1177/1097184X17753040.

Nicholas, Lucy, and Christine Agius. 2018. "\#Notallmen, \#Menenism, Manospheres and Unsafe Spaces: Overt and Subtle Masculinism in Anti-'PC' Discourse." In The Persistence of Global Masculinism, 31-59. Palgrave Macmillan, Cham. https://doi.org/10.1007/978-3319-68360-7_2.

O’Brien, Glenn. 2010. “The Style Guy: Jumpin' Jack Flash.” GQ: Gentlemens Quarterly, December 1, 2010.

O’Neill, Hugh. 2002. "Old School Rules." Men's Health 17 (8).

O'Neill, Rachel. 2018. Seduction: Men, Masculinity and Mediated Intimacy. John Wiley \& Sons.

Pascoe, C. J. 2011. "Resource and Risk: Youth Sexuality and New Media Use." Sexuality Research and Social Policy 8 (1): 5-17. https://doi.org/10.1007/s13178-011-0042-5.

Pascoe, C. J., and Sarah Diefendorf. 2018. "No Homo: Gendered Dimensions of Homophobic Epithets Online.” SocArXiv, May. https://doi.org/10.31235/osf.io/n8qpb.

Plante, Rebecca F, and Gary Alan Fine. 2017. "Sexuality and Reputation: An Introduction." Sexualities 20 (7): 767-71. https://doi.org/10.1177/1363460716679379.

Porter, Jane, and Eric Odgen. 2012. "Lust in the Office.” Men's Health 27 (7).

Powell, Anastasia, and Nicola Henry. 2017. "Sexual Violence: A Feminist Criminological Analysis." In Sexual Violence in a Digital Age, 23-47. Palgrave Studies in Cybercrime and Cybersecurity. Palgrave Macmillan, London. https://doi.org/10.1057/978-1-137-580474_2.

Robnett, Belinda, and Cynthia Feliciano. 2011. "Patterns of Racial-Ethnic Exclusion by Internet Daters." Social Forces 89 (3): 807-28.

Seal, David Wyatt, and Anke A. Ehrhardt. 2003. "Masculinity and Urban Men: Perceived Scripts for Courtship, Romantic, and Sexual Interactions with Women." Culture, Health \& Sexuality 5 (4): 295-319.

Shilling, Chris, and Philip A. Mellor. 2010. "Sociology and the Problem of Eroticism." Sociology 44 (3): 435-52.

Simon, William, and John H. Gagnon. 1986. "Sexual Scripts: Permanence and Change." Archives of Sexual Behavior 15 (2): 97-120.

Smith, Michael D., and Norman N. Morra. 1994. "Obscene and Threatening Telephone Calls to Women: Data from a Canadian National Survey." Gender and Society 8 (4): 584-96.

Stewart, Julie. 2012. "No, You're Not Perfect." Men's Health 27 (8): 172-172.

Swidler, Ann. 2003. Talk of Love: How Culture Matters. Chicago: University Of Chicago Press.

Tan, Yue, Ping Shaw, Hong Cheng, and Kwangmi Ko Kim. 2013. "The Construction of Masculinity: A Cross-Cultural Analysis of Men's Lifestyle Magazine Advertisements.” Sex Roles 69 (5-6): 237-49. 
Thelwall, Mike. 2011. "Privacy and Gender in the Social Web." In Privacy Online, edited by Sabine Trepte and Leonard Reinecke, 251-65. Berlin, Heidelberg: Springer Berlin Heidelberg.

“Tonight's the Night." 1997. Men's Health 12 (2): 129.

Uggen, Christopher, and Amy Blackstone. 2004. "Sexual Harassment as a Gendered Expression of Power." American Sociological Review 69 (1): 64-92.

Vontz, Andrew. 2008. "Break the Ice." Men's Health 23 (6): 54-56.

Wade, Lisa. 2017. American Hookup: The New Culture of Sex on Campus. 1 edition. New York, N.Y: W. W. Norton \& Company.

Waling, Andrea. 2017. "'We Are So Pumped Full of Shit by the Media' , 'We Are So Pumped Full of Shit by the Media':

Masculinity, Magazines, and the Lack of Self-Identification Masculinity, Magazines, and the Lack of Self-Identification." Men and Masculinities 20 (4): 427-52. https://doi.org/10.1177/1097184X16652654.

Wallace, Anders Axel. 2017. "Communication Games: Dating Coaches, Masculinity, and Working at Play in Seduction Communities." NORMA 12 (3-4): 286-301. https://doi.org/10.1080/18902138.2017.1312952.

web search. 2018. "Romantic or Creepy - Google Search.” August 29, 2018. https://www.google.com/\#q=romantic+or+creepy.

Weeks, Jeffrey. 1998. “The Sexual Citizen.” Theory, Culture \& Society 15 (3-4): 35-52.

Weitman, Sasha. 1998. "On the Elementary Forms of the Socioerotic Life." Theory, Culture \& Society 15 (3): 71-110.

West, Candace, and Don H. Zimmerman. 1987. "Doing Gender." Gender and Society 1 (2): 12551.

Whittier, David Knapp, and William Simon. 2001. “The Fuzzy Matrix of 'My Type’ in Intrapsychic Sexual Scripting." Sexualities 4 (2): 139-65.

Williams, Christine L., Patti A. Giuffre, and Kirsten Dellinger. 1999. "Sexuality in the Workplace: Organizational Control, Sexual Harassment, and the Pursuit of Pleasure." Annual Review of Sociology 25 (January): 73-93. 
Appendix A: Men's Consumer Magazines "Circulation averages for the six months ended: 12/31/2017"

Source: Alliance for Audited Media. 2017. “Consumer Magazines - Search Results for Men's Magazines.” Retrieved July 12, 2018. (http://abcas3.auditedmedia.com/ecirc/magform.asp).

CONSUMER MAGAZINES - SEARCH RESULTS

Search Type:SRDS Classification

Selection:'MENS'

Circulation averages for the six months ended:

Sort By:Paid Circulation - Descending

Results Found:9

Preliminary figures subject to audit as filed with the Alliance for Audited Media.

\begin{tabular}{|c|c|c|c|c|}
\hline Publication Name & $\begin{array}{r}\text { Total Paid \& Verified } \\
\text { Circulation }\end{array}$ & $\begin{array}{r}\text { Analyzed } \\
\text { Non-Paid Circu- } \\
\text { lation }\end{array}$ & $\begin{array}{r}\text { Total Paid, } \\
\text { Verified and } \\
\text { Analyzed Non- } \\
\text { Paid } \\
\text { Circulation }\end{array}$ & $\begin{array}{r}\text { Filing Sta- } \\
\text { tus }\end{array}$ \\
\hline MEN'S BOOK CHICAGO & & & & $N / F$ \\
\hline MEN'S HEALTH & $1,819,863$ & & $1,819,863$ & \\
\hline POPULAR MECHANICS & $1,208,642$ & & $1,208,642$ & \\
\hline MEN'S JOURNAL & 977,060 & & 977,060 & \\
\hline GQ GENTLEMEN'S QUART & 947,083 & & 947,083 & \\
\hline ESQUIRE & 765,702 & & 765,702 & \\
\hline OUTSIDE & 690,973 & & 690,973 & \\
\hline PLAYBOY & 321,315 & & 321,315 & \\
\hline CIGAR AFICIONADO & 257,525 & & 257,525 & \\
\hline
\end{tabular}

Filing Status: N/F - Publisher's Statement not filed by press time

T/S - Under Voluntary Temporary Suspension of Service

W - Withhold pending Publisher Materials

D/A - Data not included pending Publications Audit

Copyright (C) 12/31/2017 by Alliance for Audited Media. All rights reserved except that permission is hereby granted to reproduce excerpts if following credit line is included:

Source: Alliance for Audited Media

Snapshot Report - 12/31/2017 